there are two snags: European governments are far from persuaded that Brussels is a better custodian than they are themselves of scant research money, while this is a time when most governments are jealous of the doctrine of subsidiarity (that the centre should do only what national governments cannot). Europe is a long way from being the United States of Europe.

There are disturbing signs that Europe has not yet awakened to this gloomy prospect, or to the urgency with which it should somehow be forfended. It is conventional to speak of health and environmental quality as the benefits that European research will bring. The need that there should be a jump in economic growth comparable with that since, say, 1970, but concentrated into a decade, is in reality a more urgent social need. One of the early casualties of failure in this regard could easily be the European Union itself.

\section{Genome diversity alarms}

The excellent Human Genome Diversity Project needs better planning and a pilot project.

ProfESSOR Luigi Cavalli-Sforza, the Stanford geneticist, has an excellent idea: to reconstruct the recent history of Homo sapiens from a comparison of the genomes of different human populations. Success with what is called the Human Genome Diversity Project (HGDP) could more quickly throw more light on this important question than anything likely to be forthcoming from palaeoanthropology in the near future. But there is also the intriguing likelihood that a combination of data from both sources may make it possible to identify the genetic correlates of particular physical human adaptations, thus throwing light on the malleability of the genome as an entity. Two cheers, in all the circumstances, for Cavalli-Sforza!

Why not three cheers? Because the HGDP has insufficiently anticipated the inevitable objections to its plans. To be sure, it has been endorsed as worthy (which it is) by the Human Genome Organization (HUGO), but that is a consortium of scientists. It is also true that many of the reasons offered at last week's meeting of the Unesco's Bioethics Committee (see page 373) for declining to support Cavalli-Sforza's plans are insubstantial. For example, the working group on population genetics almost perversely confused HGDP's plans with what it called eugenics in the sense of Hitler rather than, say, Francis Galton. Similarly, it gives undue weight to the fears that the genetic inheritance of indigenous people will be exploited commercially by "vampires" doing Cavalli-Sforza's bidding.

Yet there is a nub of reason in the decision. Put simply, a genetic comparison of distinct but isolated population groups must include a comparison of the genetic constitution of what are called racial groups. It is understandable that many people (and not only those directly involved) should be alarmed at the uses to which such information could be put, while researchers cannot guarantee that the data they gather will be such that they cannot be misused; they can merely promise to use their best efforts to ensure that does not happen. Cavalli-Sforza himself says that experience so far shows that intra-group differences in physiological or psychological measures are always greater than the mean differences between groups, so that HGDP should help to combat racism. That misses the point of the objection, which is that the project may make racial members objectively identifiable, and to their disadvantage. So how should HGDP set out to win round those who doubt its motives?

The place to start is with the doctrine of informed consent, which applies to the engagement of individuals as subjects in research projects of all kinds, not just in human genetics. The purposes and procedures of the research must be fully explained, together with the objectives and the potential hazards. The understanding of the subjects must be so complete that they will be neither surprised nor disconcerted by the outcome of the projects in which they are engaged. They should agree to collaborate voluntarily. It is out of spirit with the doctrine of informed consent that people should be recruited to one project and that the same data or samples should be used for another (without informed consent to that). The principle of informed consent is excellent, and consistent with the "inherent dignity" of every person, to quote the United Nations' Universal Declaration of Human Rights (1948). The difficulty is that the extension of this principle to population groups is far from simple.

The difficulty is knowing who or what can speak for distinctive population groups. The population groups concerned are usually subgroups of national populations, but also often span frontiers. On anthropological grounds, it is estimated that there are about 5,000 population groups isolated from each other by language, geography and other factors, of which HGDP hopes to study 500. It could be imagined that the project could find islands in Polynesia or villages in New Guinea whose people would agree to give samples for the project in return for a tangible benefit of some kind, but that would offend against the voluntary principle, while the consent of a single community cannot be taken as consent by the whole of a population.

To make progress, HGDP should therefore plan to run a pilot project in circumstances in which these delicate issues would not arise, and where genetic knowledge is reasonably well spread. Almost any industrial country in Western Europe or North America would be a suitable substrate for an investigation. Data from such enquiries would bear only marginally on the grand questions of recent human evolution, but they would not be devoid of interest. Because the benefit for those taking part in the study would be that those carrying putative disease-linked alleles could be informed when appropriate and appropriately counselled, such a pilot study could help to demonstrate to indigenous people that genetic information can be beneficial and could also help to prove the counselling techniques that will be required if and when HGDP gets properly under way. 